\title{
Evaluating posture behavior during seated tasks
}

\author{
Hongwei Hsiao * and W. Monroe Keyserling \\ Center for Ergonomics. The University of Michigan, 1205 Beal Ave., Ann Artor, MI 48105, USA.
}

(Received April 4, 1991; accepted in revised form June 17, 1991)

\begin{abstract}
A method was developed to evaluate posture behavior of the trunk, neck, eye. and upper extremity in three-dimensional space during the performance of static, seated tasks. Body postures were measured using an ultrasonic measurement system to determine the Cartesian coordinates of joints and the angles between adjacent limbs. Posture preferences for a variety of visual and manual tasks were then determined.

Pilot studies using three subjects performing visual and right-handed tasks showed that the postures were affected by target location, body size, and target size. These experiments suggest that the preferred horizontal location of visual targets is within $10^{\circ}$ of the sagittal plane of the head. The preferred vertical location of visual targets is $10^{\circ}$ to $35^{\circ}$ below the seated eye height. For manual reaches, the target-to-shoulder distance should be at least one-third the length of the upper extremity to avoid extreme elbow flexion. In addition, the seat pan should swivel and should allow a person to move fore and aft in order to adjust to a comfortable work posture.
\end{abstract}

\section{Relevance to industry}

This posture evaluation method can be applied to seated work activities such as bench assembly, sewing. inspection, microscopy. VDT work, etc. The observed posture behavior patterns can then be used to develop guidelines for workstation layout to minimize postural strain during various tasks.

\section{Keywords}

Posture behavior, preferred posture, posture measurement, visual task, manual task.

\section{Introduction}

Many seated industrial tasks such as sewing, inspection, microscopy, VDT work, bench assembly, etc. require a high degree of visual activity. In turn, the visual demands of a job may determine the posture of the trunk and neck. For example, if the visual target is too low, it lies below a comfortable viewing angle and may require neck flexion and/or trunk flexion. Similarly, many industrial

\footnotetext{
* Correspondence address: H. Hsaio, SCS, PTB, DSR, NIOSH, 944 Chestnut Ridge Rd., Morgantown. WV 26505, USA.
}

jobs involve some type of manual manipulations. Because the body is a kinematic linkage, the positions of the hands determine the postures of the wrists, elbows, shoulders, and sometimes the posture of the trunk. If the manual target is too low, trunk flexion may be required. If the target is too high, flexion or abduction of the upper arm may be required. While posture is strongly influenced by workstation layout, the relationships among job demands, workstation layout, and posture are poorly understood.

Existing posture prediction techniques, such as stick figures and manikin methods (Drillis and Contini, 1966; Dempster, 1955; Carlyle, 1960) have been used to determine work posture based on 
link lengths and anatomical range-of-motion data. In these methods, the 'links' are manipulated to obtain feasible postures. Although these methods are useful for finding feasible postures for seated work, they do not necessarily predict the postures that people actually use because they lack information regarding postural behavior. Furthermore, although a number of computerized kinematic models (Healy et al., 1969; Bapu et al., 1982; Kilpatrick, 1970; Snyder et al., 1972) have been developed and used to predict postures for specific seated tasks, a back/pelvic support and/or seat belts were present when collecting the empirical data to develop these models, thus limiting free movement of the hips. These models are not necessarily suitable for predicting preferred postures for industrial jobs where no seat belt is used and the worker may move freely. In order to develop a model of posture for the unconstrained working conditions (i.e., no seat belt) found in most industries, it is first necessary to understand postural behavior and posture preferences for simple tasks.

To achieve this goal, a technique for evaluating posture behavior was developed. Pilot studies of posture behavior during simple visual tasks and right-handed reach tasks were performed to evaluate the method.

\section{Objective}

The objective of this study was to develop a method for evaluating how people adapt trunk, neck, upper extremity, and eye (i.e. viewing angle) postures while performing various tasks. This included: (1) a determination of the task factors which influenced these postures, and (2) a determination of preferred postures.

\section{Method}

\section{Definitions}

Assume that a seated worker can be represented by the system of links shown in figure 1: a hand-to-wrist link, a lower arm link, an upper arm link, and a claviscapular link for each upper extremity, plus an eye-to-target link, a head/neck link, a torso link, and a pelvis link. Several terms to describe posture behavior are defined and presented in the appendix.

\section{Posture classification}

The joint angles/segment postures (i.e. hip shifting, hip rotation, viewing angles. neck/head angles, trunk angles, and upper extremity postures) are defined and presented in the appendix. The neutral, effort, and maximum posture ranges of the body segments and the signs of the directional rotation of the segment postures are also listed in the appendix.

\section{Apparatus}

The following items were obtained or constructed for use in the study:

Anthropometer: An anthropometer (sliding calipers, GMP brand) was used to measure the subjects' eye heights, shoulder height, and segment lengths.

Target matrix: An adjustable target matrix (figure 2) had 27 holes and 27 arms (aluminum bars) to position the 27 target locations.

Landolt rings: Three sets of Landolt rings were used to form three levels of visual target size $\left(0.7^{\prime}\right.$, $1.2^{\prime}$, and $1.7^{\prime}$ visual angles at the fixed target-eye distance; see figure $3 \mathrm{c}$ ).

Hand grip: Two spherical rubber hand grips ( $7.1 \mathrm{~cm}$ diameter) were used as the manual targets. They could be gripped with any orientation of the hands. The grips could be attached to or released from the target matrix to establish the supported or non-supported treatments (see figure 4d).

Chair: The subjects performed the task while seated on a chair. The chair had an adjustable seat-pan height (range $35.8 \mathrm{~cm}$ to $48.8 \mathrm{~cm}$ ) to accommodate anthropometries varying from the 99th percentile male to the 1st percentile female. There were neither armrests nor a back-rest on the experimental chair.

Ultrasonic measurement system: An ultrasonic measurement system (Hsiao and Keyserling, 1990) with 14 transmitters and 8 receivers was used to measure the location of the selected joints in three-dimensional space (figure 2). The system was controlled by a personal computer (IBM PC) using an ultrasonic card (UDM-PC by Microproducts Inc., Vermont). The transmitters can be mounted on the body joints. The eight receivers 
were set around the apparatus so that the signal generated from each transmitter could be received by at least three receivers.

Pilot study I: Posture behavior during static, seated visual tasks

\section{Hypotheses}

The following hypotheses describing postural behavior were proposed:
(1) Segment postures during visually demanding tasks are affected by visual target position, target size (i.e. visual angle), and body size.

(2) A person will keep each segment as close to the neutral posture as possible.

(3) If necessary, a person will move the segments away from a neutral posture. $\mathrm{He} / \mathrm{she}$ is more likely to move the distal segments than the proximal segments.

(4) If a visual target is too small or the target location is too far to the left or right. the

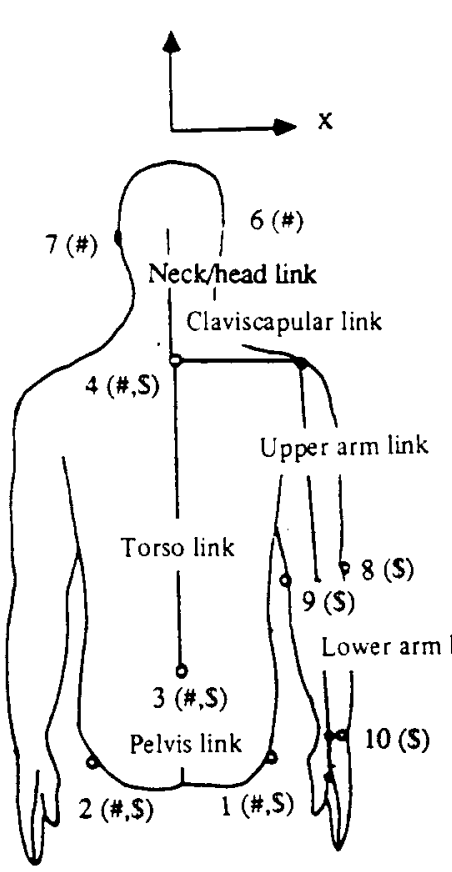

a. Posterior view
Z

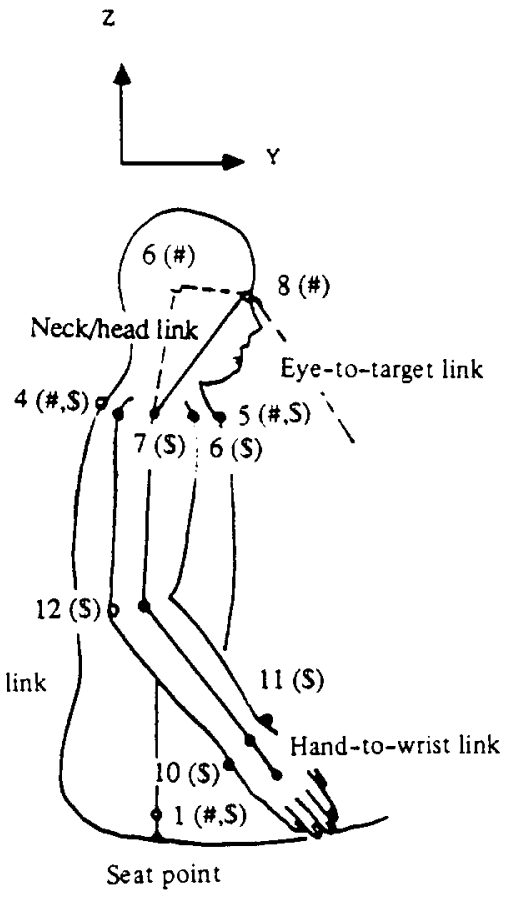

b. Right side view

\footnotetext{
Transmitters 1\&2 (\#,\$): the two lateral-surface marks of the hip joint Transmitter $3(\#, \$)$ : the back-surface mark of the 5th lumbar vertebra (L5)

Transmitter 4 (\#,\$): the back-surface mark of the 2 nd thoracic vertebra (T2)

Transmitter $5(\#, S)$ : the suprastemale notch (the front-surface mark of T2)

Transmitter 6 (\#): right tragion (right ear)

Transmitter 7 (\#): left tragion (left ear)

Transmitter 8 (\#): the eye

Transmitter $6(\$)$ : the anterior side of the lesser tubercle of the right shoulder joint

Transmitter $7(\$)$ : the posterior side of the greater tubercle of the right shoulder joint

Transmitter 8 (\$): the medial side of the right elbow

Transmitter 9 (\$): the lateral side of the right elbow

Transmitter 10\& 11 (S): the medial and lateral sides of the right wrist

Transmitter 12 (\$): the surface of the olecranon of the right elbow

\# For Pilot Study I : Visual task

\$ For Pilot Study II : Right-handed reach
}

Fig. 1. Seated body linkage system. 
operator will shift hips on the seat in order to view the target.

\section{Experimental design}

The dependent variables (see figures $\mathrm{A} 1$ and $\mathrm{A} 2$ in the appendix) were the joint angles as follows:

(1) mid-hip shifting distance and hip rotation angle,

(2) viewing angles relative to Frankfurt and sagittal planes (two degrees of freedom: vertical and horizontal),

(3) neck/head joint angles (three degrees of freedom: vertical, twist, and lateral bending angles),

(4) trunk joint angles (three degrees of freedom: vertical, twist, and lateral bending angles).

The independent variables (figure 3 ) included:

(a) target vertical location (vertical angle of eyetarget line relative to the upright, seated Frankfurt plane),

(b) target horizontal location (horizontal angle of eye-target line relative to the sagittal plane of the head in its neutral position),

(c) target size (visual angle in minutes), (d) body size (subject anthropometry): body height,

(e) replication (experimental day) effect,

(f) fatigue effect.

\section{Design}

A $3 \times 3 \times 3 \times 3$ full factorial design in three blocks with 2 replications and 3 measurements for each cell were used for the experiment (see figure 3 ). The first three factors were (a) target vertical location, (b) target horizontal location, and (c) target size. The three levels of the target vertical location were $-60^{\circ}$ (below eye height), $0^{\circ}$ (eye height), and $60^{\circ}$ (above eye height); the three levels of the target horizontal location were $-60^{\circ}$ (i.e. $60^{\circ}$ right of the sagittal plane), $-30^{\circ}$ (i.e. $30^{\circ}$ right of the sagittal plane), and $0^{\circ}$ (on the sagittal plane); and the three levels of target size were $0.7^{\prime}, 1.2^{\prime}$, and $1.7^{\prime}$. Three subjects with different statures (and thus seated eye heights) were used as three blocks. The replication was (e) the day effect (day 1 versus day 2); the repeated measurement was (f) the fatigue effect during a single treatment. The dependent variables obtained were joint angles in degrees.

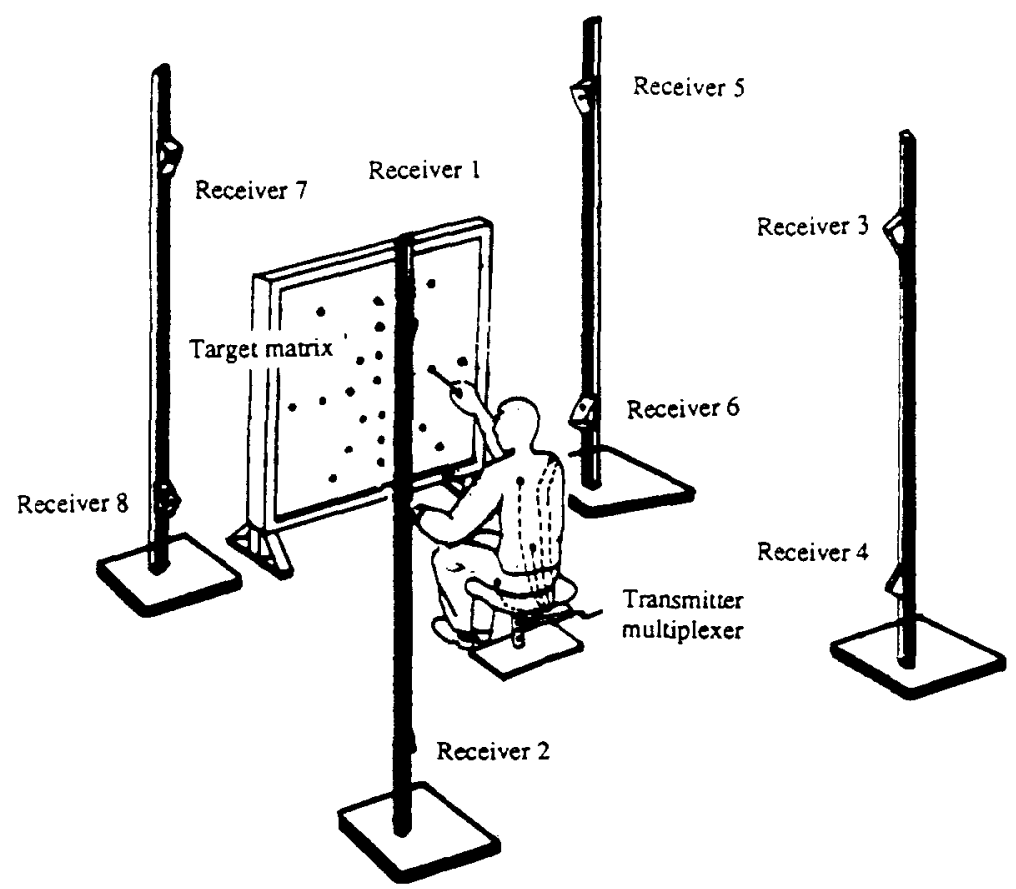

Fig. 2. The experimental apparatus. 


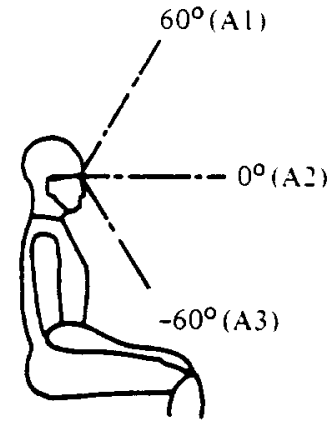

a. Target vertical location

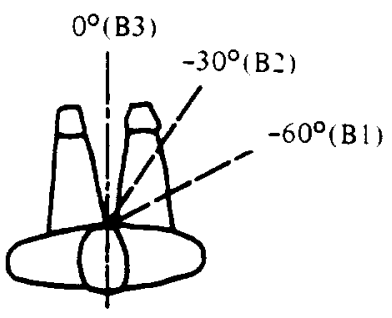

b. Target horizontal location

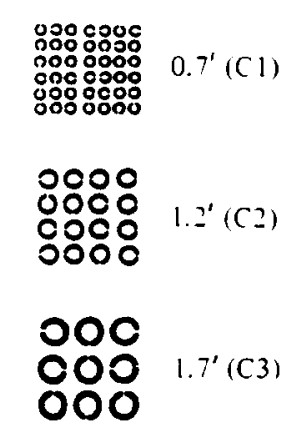

target-eye distance $=101.6 \mathrm{~cm}$

c: Target size
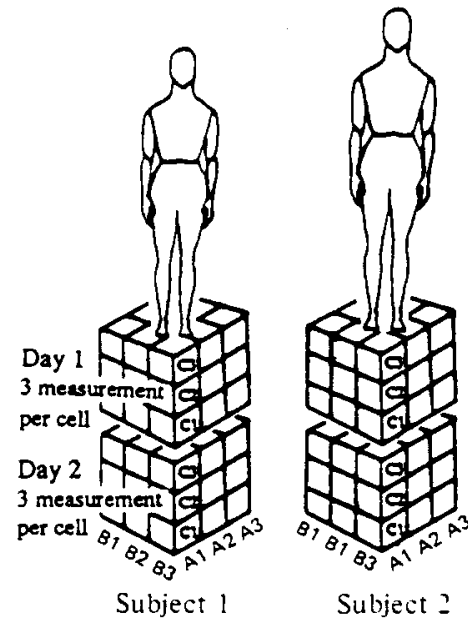

Subject ?

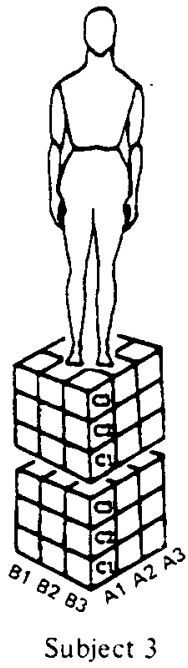

d. Body size and design structure

Fig. 3. The independent variables and design structure for the visual experiment.

\section{Subjects}

Three volunteer subjects were recruited from a university student population. They were not selected at random, but were chosen to represent people of tall, medium, and short stature. One subject (152.6 cm stature, female) was slightly shorter than a 5 th percentile US female; one subject $(171 \mathrm{~cm}$ stature, male) was slightly taller than a 50th percentile US male; and the third subject (186 cm stature, male) was at about the 95th percentile of the US male population (Webb Associates, 1978). A vision test was performed to assure that all subjects had 20/20 (or better) vision, either uncorrected or corrected with contact lenses. Subject participation was on an informed consent and paid basis.

\section{Procedure}

At the beginning of the experiment, anthropometric measurements were obtained using a set of sliding calipers. Following these measurements, the subjects were seated upright with their hands at rest on their thighs, looking straight ahead, facing the target matrix. Eight transmitters were mounted on the two lateral-surface marks of the hip joint, the back-surface mark of the 5th lumbar vertebra (L5), the back-surface mark of the 2nd thoracic vertebra (T2), the suprasternale notch (the front-surface mark of $\mathrm{T} 2$ ), the two lateral sides of the tragia (approximately the earholes). and the center eye position (see figure 1). No restraints, such as lap belts or shoulder harnesses, were imposed on the subjects. The lighting was 
Table I

Results of analysis of variance for trunk vertical angle.

\begin{tabular}{|c|c|c|c|c|}
\hline Source & $D F$ & Mean-square & Sig. $(p)$ & $R^{2}$ \\
\hline Target ver. location & 2 & 45825.0 & $<0.001^{\mathrm{a}}$ & 0.73 \\
\hline Target hor. location & 2 & 12.4 & n.s. & $<0.01$ \\
\hline Target size (vis. ang.) & 2 & 503.9 & $<0.001$ & 0.01 \\
\hline Body size & 2 & 162.5 & 0.04 & $<0.01$ \\
\hline Day (replication) & 1 & 214.0 & 0.04 & $<0.01$ \\
\hline Fatigue (rep. meas.) & 2 & 1.7 & n.s. & $<0.01$ \\
\hline Ver. loc. hor. loc. & 4 & 163.3 & 0.012 & $<0.01$ \\
\hline Ver. loc. tgt. size & 4 & 269.1 & $<0.001$ & 0.01 \\
\hline Ver. loc, body size & 4 & 1744.1 & $<0.001^{a}$ & 0.06 \\
\hline Hor. loc. * tgt. size & 4 & 171.8 & 0.009 & $<0.01$ \\
\hline Hor. loc. " body size & 4 & 41.8 & n.s. & $<0.01$ \\
\hline Tgt. size * body size & 4 & 208.9 & 0.003 & 0.01 \\
\hline Error & 450 & 50.3 & & 0.13 \\
\hline
\end{tabular}

n.s.: no statistical significance $(p>0.05)$.

${ }^{3}$ Both statistically and practically significant $\left(p<0.05\right.$ and $R^{2}>0.05$ ).

Table 2

Summary of significant levels ( $p$-value) for the dependent variables.

(2a) Analysis of main effect

\begin{tabular}{|c|c|c|c|c|c|c|}
\hline $\begin{array}{l}\text { Segment posture } \\
\text { (depend. variables) }\end{array}$ & $\begin{array}{l}\text { Ver. target } \\
\text { location }\end{array}$ & $\begin{array}{l}\text { Hor. target } \\
\text { location }\end{array}$ & $\begin{array}{l}\text { Target size } \\
\text { (visual ang.) }\end{array}$ & $\begin{array}{l}\text { Body } \\
\text { size }\end{array}$ & Day & Fatigue \\
\hline Hip-shifting dist. & $<0.001^{\mathrm{a}}$ & $<0.001^{a}$ & $<0.001$ & $<0.001^{\mathrm{a}}$ & n.s. & n.s. \\
\hline Hip rotation angle & $<0.001$ & $<0.001^{a}$ & 0.046 & $<0.001$ & 0.016 & n.s. \\
\hline Trunk hor. angle & $<0.001$ & $<0.001^{a}$ & 0.003 & $<0.001$ & 0.019 & n.s. \\
\hline Trunk ver. angle & $<0.001^{\mathrm{a}}$ & n.s. & $<0.001$ & 0.040 & 0.004 & a.s. \\
\hline Trunk twist angle & $<0.001$ & $<0.001^{\mathrm{a}}$ & n.s. & $<0.001^{\mathrm{a}}$ & n.s. & n.s. \\
\hline Neck/head hor. ang. & $<0.001$ & $<0.001^{\mathrm{a}}$ & n.s. & $<0.001$ & n.s. & n.s. \\
\hline Neck/head ver, ang. & $<0.001^{a}$ & $<0.001$ & 0.035 & $<0.001$ & n.s. & n.s. \\
\hline Neck/head twist ang. & $<0.001^{\mathrm{a}}$ & $<0.001$ & 0.012 & $<0.001$ & n.s. & n.s. \\
\hline Hor. viewing ang. & $<0.001^{\mathrm{a}}$ & n.s. & 0.026 & $<0.001^{\mathrm{a}}$ & $<0.001$ & n.s. \\
\hline Ver. viewing ang. & $<0.001^{\mathrm{a}}$ & n.s. & n.s. & $<0.001^{a}$ & n.s. & n.s. \\
\hline \multicolumn{7}{|c|}{ (2b) Analysis of interaction effect ${ }^{b}$} \\
\hline $\begin{array}{l}\text { Segment posture } \\
\text { (depend. variables) }\end{array}$ & $\begin{array}{l}\text { Ver. loc. } \times \\
\text { hor. loc. }\end{array}$ & $\begin{array}{l}\text { Ver. loc. } \times \\
\text { tgt. size }\end{array}$ & $\begin{array}{l}\text { Ver. loc. } \times \\
\text { body size }\end{array}$ & $\begin{array}{l}\text { Hor. loc. } X \\
\text { tgt. size }\end{array}$ & $\begin{array}{l}\text { Hor. loc. } x \\
\text { body size }\end{array}$ & $\begin{array}{l}\text { Tgt. size } x \\
\text { body size }\end{array}$ \\
\hline Hip-shifting dist. & $<0.001^{\mathrm{a}}$ & $<0.001$ & $<0.001$ & n.s. & $<0.001$ & $<0.001$ \\
\hline Hip rotation angle & $<0.001$ & n.s. & $<0.001$ & $<0.001$ & $<0.001$ & n.s. \\
\hline Trunk hor. angle & $<0.001^{\mathrm{a}}$ & $<0.001^{\mathrm{a}}$ & $<0.001^{\mathrm{a}}$ & $<0.001$ & n.s. & $<0.001$ \\
\hline Trunk ver. angle & 0.012 & $<0.001$ & $<0.001^{\mathrm{a}}$ & 0.009 & n.s. & 0.003 \\
\hline Trunk twist angle & $<0.001^{\mathrm{a}}$ & 0.018 & $<0.001^{a}$ & n.s. & $<0.001$ & 0.016 \\
\hline Neck/head hor. ang. & $<0.001^{\mathrm{a}}$ & n.s. & 0.013 & n.s. & n.s. & n.s. \\
\hline Neck/head ver. ang. & $<0.001$ & $<0.001$ & $<0.001$ & 0.015 & 0.001 & 0.001 \\
\hline Neck/head twist ang. & $<0.001^{\mathrm{a}}$ & 0.025 & $<0.001$ & n.s. & 0.004 & 0.039 \\
\hline Nor, viewing ang. & $<0.001^{\mathrm{a}}$ & n.s. & $<0.001^{\mathrm{a}}$ & 0.026 & $<0.001$ & n.s. \\
\hline Ver. viewing ang. & $<0.001$ & $<0.001^{\mathrm{a}}$ & $<0.001^{a}$ & 0.025 & 0.007 & 0.001 \\
\hline
\end{tabular}

n.s.: no statistical significance $(p>0.05)$

Both statistically and practically significant ( $p<0.05$ and $R^{2}>0.05$ ).

b $99 \%$ of the third and higher order interactions were not statistically or practically significant. 
controlled $56 \pm 3$ foot-candles for all the visual targets. When the treatment combination had been established, the subjects were instructed to view the target in the posture that was most natural and to identify the orientations of the opening slits of the Landolt rings. Each subject received five minutes of training and practice with the viewing task. After the instruction and practice session, experimental data collection began. Each subject performed the task for two minutes at each treatment to adjust to a comfortable posture. In order to test for fatigue, three measurements were repeated during the two minutes (at 40 seconds, 80 seconds, and 120 seconds elapsed time). During the experiment, the twenty-seven treatment combinations were performed in random order for two replications (one replication per day on two days).

After completing a treatment (i.e. 2 minutes), the subjects rested for a minimum of one minute (and then returned to the upright posture for the next treatment). After every nine treatments, the subjects rested for 20 minutes. After the rest period, posture was measured in the normal erect sitting to obtain the neck/head normal tilt angle from the upright position.

\section{Results}

Various statistical analyses were performed corresponding to each of the four hypotheses. The results of these analyses are presented below.

\section{Factor effects}

An analysis of variance was performed for each of the dependent variables to determine the significance of the independent variables: (a) target vertical location, (b) target horizontal location, (c) target size, (d) and body size (stature) on body posture. The (e) replication difference (day effect) and (f) fatigue effect were also evaluated.

The MGLH Analysis of Variance program (Systat Inc., 1985) was used to determine the significance of the independent variables. An example of this analysis for the trunk vertical (flexion/extension) angle as the dependent variable is shown in table 1 . The results for all the dependent variables are summarized in table 2 . For most of the dependent variables (i.e. trunk angles, neck angles, and viewing angles etc.), statistically sig- nificant relationships to the independent variables (a), (b), (c), (d), and (e) were found as well as to some interactions. No significant relationship to fatigue was found. Although some main effects and interactions were statistically significant, their simple coefficients of determination $\left(R^{2}\right)$ indicated that their contributions to the total variance were sufficiently small to be of no practical significance $\left(R^{2}<0.05\right)$. As a result, typically only two or three main effects and one or two interactions were important to a dependent variable. For example, for the trunk vertical angle as the dependent variable, a very large fraction of variance was explained by the target vertical location (73\%) and the target vertical location $\times$ body size interaction $(6 \%)$, while a relatively small fraction of variance was explained by the other factors and their interactions (table 1). Therefore, the trunk vertical angle could be explained simply on the basis of the target vertical location and body size.

In general, the experimental Hypothesis 1 was supported by the data. Operators' segment postures were affected by the visual target location (vertical and horizontal), target size, and body size (stature). However, the contribution of target size (at the $0.7^{\prime}, 1.2^{\prime}$, and $1.7^{\prime}$ levels) to the segment postures was small relative to that of the other factors.

Preferred postures and deviations from neutral postures

The measured joint angles were classified into two categories: within the neutral range and out of the neutral range. The number of observations in the neutral range was converted to percentage relative to the total observations (81 observations) for each replication for each subject. Student $t$ tests were performed to test if at least 50\%, 70\%, and $90 \%$ of the 'observed' joint angles were in the defined range of neutral posture (see table AI in the appendix) for each segment/joint. The results (table 3 ) showed that, in most cases, $70 \%$ or more of the 'observed' joint angles were in the neutral range except the neck/head vertical angle.

\section{Relative neutral-tendencies among body segments}

A descriptive analysis was performed to assess the neutral-tendency for each of the dependent 
Table 3

The observed postures within the neutral range during visual tasks (see table $\mathrm{Al}$ in the appendix for definition of neutral range).

\begin{tabular}{lllll}
\hline Segment posture & $\begin{array}{l}\text { Mean } \pm \\
\text { std. dev. } \\
(\%)\end{array}$ & \multicolumn{3}{l}{$\begin{array}{l}\text { Within the neutral } \\
\text { range }\end{array}$} \\
\cline { 4 - 5 } & & $50 \%$ & $70 \%$ & $90 \%$ \\
\hline Trunk lat. angle & $98 \pm 2$ & Yes & Yes & Yes \\
Trunk ver. angle & $82 \pm 13$ & Yes & Yes & No \\
Trunk twist angle & $95 \pm 4$ & Yes & Yes & Yes \\
Neck/head lat. angle & $92 \pm 6$ & Yes & Yes & No \\
Neck/head ver. ang & $74 \pm 12$ & Yes & No & No \\
Neck/head twist angle & $84 \pm 11$ & Yes & Yes & No \\
Hor. viewing & $99 \pm 1$ & Yes & Yes & Yes \\
Ver. viewing & $84 \pm 9$ & Yes & Yes & No \\
\hline
\end{tabular}

variables. The total variance of all observations was computed for each dependent variable and used to measure neutral-tendency of segment postures. An $F$-test was performed to compare the total variance of each pair of adjacent segments/ joints. For both fore-and-aft and left-and-right movements, the total variance of the neck/head was greater than that of the trunk, and the variance of the trunk was greater than that of the eyes. For the twisting motions, the total variance of the hips (rotation) was greater than that of the neck/head, and the variance of the neck/head was greater than that of the trunk. That is, the trunk was found to have a greater neutral-tendency than the neck/head in fore-and-aft move- ment (flexion/extension). left-and-right movement (lateral bending) and twist (rotation): the eyes had greater neutral-tendency than the other segments in both vertical and horizontal directions; and the hips had less neutral-tendency than the other segments in rotation (twist). These findings partially confirmed experimental Hypothesis 3.

Shifting of seat location (hip-shifting) at different factor levels

The main effects analyses (table 4) showed that subjects shifted their hips when the target location was too far to the right of the sagittal plane. Although the contribution of target size to the hip-shifting was relatively small $\left(R^{2}<0.05\right)$, its contribution was statistically significant (tables 2 and 4). This behavior was consistent with $\mathrm{Hy}$ pothesis 4 .

The hip-rotation angle was determined mainly on the basis of the target horizontal location (table 2). The hip rotation at the $-60^{\circ}$ target horizontal location was greater than that at the $-30^{\circ}$ location, and the rotation at the $-30^{\circ}$ location was greater than that at $0^{\circ}$ location (table 4). This finding implies that a swiveling seat would be beneficial for workers who must move their heads and upper bodies in response to task demands. This result was consistent with the preference of a free-swivel feature for industrial seats as suggested by Yu et al. (1988).

Table 4

Summary of the differences ${ }^{3}$ of hip-shifting at different factor levels.

(4a) Analysis of main effect for hip-shifting distance

\begin{tabular}{lcll}
\hline Factors & & Shifting distance & Differences \\
\hline Target horizontal location & $0^{\circ}(\mathrm{H} 1)$ & $4.6 \pm 4.7 \mathrm{~cm}$ & $\mathbf{H} 1 \mathrm{H} 2<\mathrm{H} 3$ \\
& $-30^{\circ}(\mathrm{H} 2)$ & $5.4 \pm 5.3 \mathrm{~cm}$ & \\
& $-60^{\circ}(\mathrm{H} 3)$ & $7.5 \pm 3.0 \mathrm{~cm}$ & $\mathbf{S 3} \mathbf{S}<\mathrm{S} 1$ \\
Target size (visual angle) & $0.7^{\prime}(\mathrm{S} 1)$ & $6.6 \pm 5.3 \mathrm{~cm}$ & \\
& $1.2^{\prime}(\mathrm{S} 2)$ & $5.5 \pm 4.3 \mathrm{~cm}$ & \\
& $1.7^{\prime}(\mathrm{S} 3)$ & $5.3 \pm 4.0 \mathrm{~cm}$ & Differences \\
(4b) Analysis of main effect for hip-rotation angle & & H3 $<\mathrm{H} 2<\mathrm{H} 1$ \\
\hline Factors & & Hip rotation angle & \\
\hline Target horizontal location & $0^{\circ}(\mathrm{H} 1)$ & $-2^{\circ} \pm 2^{\circ}$ & $-25^{\circ} \pm 9^{\circ}$ \\
& $-30^{\circ}(\mathrm{H} 2)$ & $-46^{\circ} \pm 8^{\circ}$ & \\
& $-60^{\circ}(\mathrm{H} 3)$ & &
\end{tabular}

\footnotetext{
${ }^{2}$ Mean \pm standard deviation (sample size $n=162$ ).
}

Bold: no significant difference between levels. 
Pilot study II: Posture behavior during static, seated right-handed tasks

\section{Hypotheses}

The following hypotheses describing postural behavior were proposed:
(1) Postures during manual reach tasks are affected by target locations, target types. and body size.

(2) A person will keep each segment as close to the neutral posture as possible.

(3) If necessary, a person will move segments away from a neutral posture. $\mathrm{He} /$ she is more

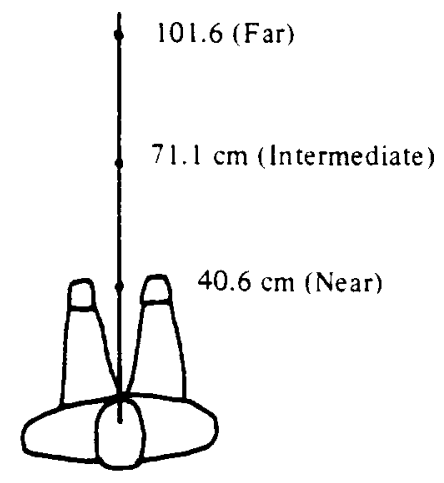

a: Target distance

$0^{\circ}$ (Sagittal plane)

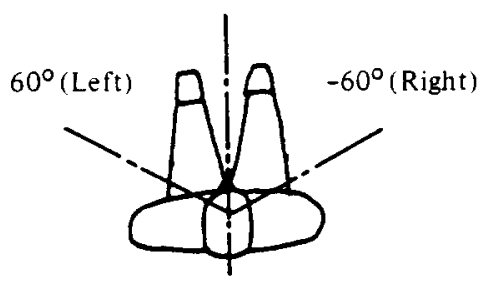

c: Target horizontal location

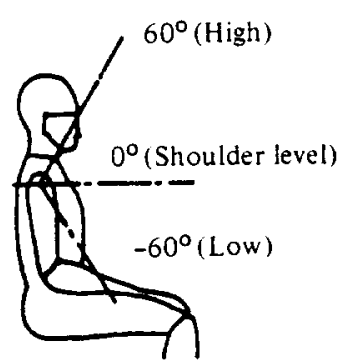

b: Target verical location

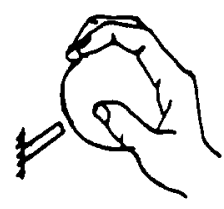

Non-supported

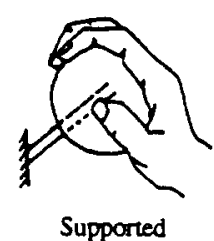

d: Target type

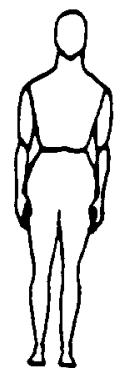

Subject 3 (Tali)

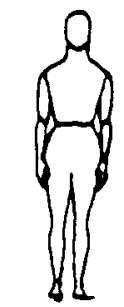

Subject 1 (Short)

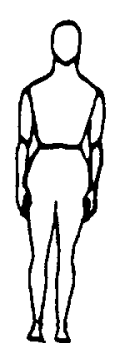

Subject 2 (Medium)

e: Body sizc

Fig. 4. Independent variables for manual tasks. 
likely to move the distal segments than the proximal segments.

(4) If the distance between a target and the shoulder position for an upper extremity is greater than the length of the upper extremity, the operator will shift hips on the seat rather than flex or twist the trunk when reaching to the targets.

\section{Experimental design}

The-dependent variables (see figures $\mathrm{Al}$ and A2 in the appendix) were the following:

(1) mid-hip-shifting distance and hip-rotation angle,

(2) trunk angles (flexion-extension, lateral bending, and twist),

(3) shoulder angles (flexion-extension, adduction-abduction, and humeral rotation),

(4) elbow angle (included angles),

(5) forearm-rotation angle,

(6) wrist angles (flexion-extension and radialulnar deviation).

The independent variables (see figure 4) included:

(1) the distance from target to the shoulder (T2, the second thoracic vertebra when sitting upright),

(2) the vertical angle of the T2-to-target vector relative to the transverse plane of the trunk in its upright position,

(3) the horizontal angle of the T2-to-target vector relative to the sagittal plane of the trunk in its upright position,

(4) the type of support used to hold the manual targets, and

(5) the anthropometry of the subjects.

\section{Design}

A $1 / 2$ fraction of a $2 \times 3^{4}$ factorial block design (Connor and Young, 1961) was used for the experiment. Two replications and three repeated measurements were performed for each cell. The three repeated measurements were obtained during a two-minute static reach (postures were measured at 40,80 , and 120 seconds during the reach). The first four factors were the following independent variables: (a) target distance, (b) target vertical location, (c) target horizontal location, and (d) target support type. The three levels of the target distance were $40.6 \mathrm{~cm}$ (short), $71.1 \mathrm{~cm}$ (intermediate), and $101.6 \mathrm{~cm}$ (far). (Note that shoulderto-hand length is approximately $62.5 \mathrm{~cm}$ for the 50 th percentile US female, and $67.7 \mathrm{~cm}$ for the 50 th percentile US male. The three levels of the target vertical location were $-60^{\circ}$ (low), $0^{\circ}$ (shoulder height), and $60^{\circ}$ (high); the three levels of the horizontal target location were $-60^{\circ}$ (right). $0^{\circ}$ (center), and $60^{\circ}$ (left): and the two levels of the target support type were supported versus non-supported. Three subjects with different statures were used as three blocks. The replication was the day effect (day 1 versus day 2). Fatigue was evaluated by three repeated measurements during a single treatment. The dependent variables obtained were joint angles in degrees.

\section{Subjects}

Three volunteer subjects were recruited from a university student population. They were not selected at random, but were chosen to represent people of short, medium, and tall stature (the 5th. 50 th, and 95 th percentiles of the overall US population). The subjects were all in good health and had no history of significant musculoskeletal injury or disease. Subject participation was on an informed consent and paid basis.

\section{Procedure}

At the beginning of the experiment, anthropometric measurements were obtained. Following these measurements, the subjects were seated with their hands at rest on their thighs, looking straight ahead, facing the target matrix, and the transmitters were mounted on the joints. 12 transmitters were used during the experiment. They were mounted on the two lateral-surface marks of the hip joints, the back-surface mark of the 5th lumbar vertebra (L5), the back-surface mark of the 2nd thoracic vertebra (T2), the suprasternale notch (the front-surface mark of T2), the anterior side of the lesser tubercle and the posterior side of the greater tubercle of the right shoulder joint, the lateral and medial sides of the right elbow, the lateral and medial sides of the right wrist, and the surface mark of the olecranon of the right elbow (see figure 1). No restraints, such as lap belts or 
shoulder harnesses, were imposed on the subjects. Each of the three subjects was assigned 27 treatments $(1 / 2$ fractional factorial design). When the treatment condition had been established, the subjects were instructed to grasp the targets in the posture that was most natural. Each subject received five minutes of training and practice with the task. After the instruction and practice session, data collection was initiated. Each subject performed the task for 2 continuous minutes at each treatment. During this period the subject was allowed to adjust to a more comfortable posture if necessary. Three measurements were taken during the two minutes (at 40 seconds, 80 seconds, and 120 seconds elapsed time). Two replications were performed on different days.

After completing a treatment (one reach, 2 minutes elapsed time), the subjects rested for a minimum of one minute (and then returned to the upright posture for the next treatment). After every nine treatments, the subjects rested for 20 minutes.

\section{Results}

Statistical analyses were performed corresponding to each of the four hypotheses. The results of these analyses are presented below.

\section{Factor effects}

An analysis of variance was performed for each of the dependent variables to determine the significance of the independent variables on body posture. The replication (day effect) and fatigue effect were also evaluated.

During the experiment, the subjects stood up in response to three treatments with high target locations due to excessive reach requirements. These treatments were dropped during the data analysis because the objective of the study was to investigate seated posture behavior (that is, 432 observations were used in the analysis instead of 486 observations). As a result, the interaction between the target distance and target vertical location could not be evaluated with the original three distance levels due to confounding with the error term. This interaction was approximated using the data with short and intermediate distances. Refer to 'Experiment Design' in Discussion section below for discussion.

The results of main effects for all of the dependent variables are summarized in table 5. For most of the dependent variables (i.e. trunk angles, shoulder angles, and wrist angles, etc.), statistically significant relationships were found to one or more of the target (distance, location, and/or

Table 5

Summary of simple coefficients of determination $\left(R^{2}\right)$ for the dependent variables. (Analysis of the main effects for right-handed reach.)

\begin{tabular}{|c|c|c|c|c|c|c|c|c|}
\hline $\begin{array}{l}\text { Segment posture } \\
\text { (depend. variables) }\end{array}$ & $\begin{array}{l}\text { Target } \\
\text { dist. }\end{array}$ & $\begin{array}{l}\text { Ver. tgt. } \\
\text { location }\end{array}$ & $\begin{array}{l}\text { Hor. tgt } \\
\text { location }\end{array}$ & $\begin{array}{l}\text { Target } \\
\text { type }\end{array}$ & $\begin{array}{l}\text { Body } \\
\text { size }\end{array}$ & Rep. & Fatigue & $\begin{array}{l}\text { Std. } \\
\text { dev }\end{array}$ \\
\hline Hip-shifting dist. & $0.285^{b}$ & $0.130^{b}$ & 0.021 & 0.001 & $0.100^{b}$ & 0.001 & 0.001 & $3 \mathrm{~cm}$ \\
\hline Hip rotation angle & 0.002 & 0.001 & $0.730^{\mathrm{b}}$ & 0.001 & 0.001 & 0.001 & 0.001 & $10^{\circ}$ \\
\hline Trunk lat. bending & 0.016 & $0.127^{b}$ & $0.113^{b}$ & 0.011 & $0.089^{b}$ & 0.001 & 0.001 & $5^{\circ}$ \\
\hline Trunk flex-ext. & $0.525^{b}$ & $0.104^{b}$ & 0.001 & 0.002 & $0.069^{b}$ & 0.001 & 0.001 & $8^{\circ}$ \\
\hline Trunk twist angle & $0.057^{b}$ & $0.078^{b}$ & $0.160^{b}$ & 0.041 & 0.017 & 0.001 & 0.001 & $8^{\circ}$ \\
\hline Shoulder add -abd. & $0.080^{b}$ & $0.121^{b}$ & $0.132^{b}$ & 0.001 & 0.015 & 0.001 & 0.001 & $20^{\circ}$ \\
\hline Shoulder flex.-ext. & $0.195^{b}$ & $0.700^{b}$ & 0.019 & 0.001 & 0.007 & 0.001 & 0.001 & $9^{\circ}$ \\
\hline Humeral rot. angle & $0.069^{b}$ & 0.027 & 0.020 & $0.065^{b}$ & 0.035 & 0.001 & 0.001 & $22^{\circ}$ \\
\hline Elbow angle & $0.760^{b}$ & 0.022 & 0.009 & 0.001 & $0.056^{\mathrm{b}}$ & 0.001 & 0.001 & $9^{\circ}$ \\
\hline Forearm rot. angle & 0.034 & $0.078^{b}$ & 0.044 & 0.028 & 0.032 & 0.010 & 0.001 & $35^{\circ}$ \\
\hline Wrist flex.-ext. & 0.017 & $0.126^{b}$ & 0.014 & 0.042 & 0.027 & 0.003 & 0.001 & $13^{\circ}$ \\
\hline Wrist deviation & 0.010 & 0.023 & $0.056^{b}$ & 0.001 & 0.002 & 0.015 & 0.001 & $14^{\circ}$ \\
\hline
\end{tabular}

\footnotetext{
The standard deviation of joint angles about regression lines which involves the above 7 main effects and 9 interactions (not shoun in the table).

Both statistically and practically significant $\left(p<0.05\right.$ and $\left.R^{2}>0.05\right)$.
} 
support) and body-size independent variables as well as to some interactions. No significant relationship to replication (day effect) or fatigue were found. Although many main effects and interactions were statistically significant, their simple coefficients of determination $\left(R^{2}\right)$ indicated that their contributions to the total variance of the dependent variables were sufficiently small to be of no practical significance $\left(R^{2}<0.05\right)$. As a result, typically only two or three main effects and one or two interactions were both statistically and practically important.

In general, Hypothesis 1 was supported by the results. Most measured postures were affected by the manual target location (i.e. distance, vertical location, and horizontal location) and/or body size (stature). A few postures were also affected by the target support type.

\section{Preferred postures and deviations from neutral pos- tures}

The measured joint angles were classified into two categories: within the neutral range and out of the neutral range (see table A1 in the appendix). The number of observations in the neutral range was converted to a percentage relative to the total observations ( 72 observations) for each replication for each subject. Student $t$-tests were performed to test if at least $30 \%, 50 \%, 70 \%$, and $90 \%$ of the 'observed' joint angles were in the defined range of neutral posture for each segment/joint. The results (table 6) showed that the mean percentages of the 'observed' joint angles in the neutral range varied from $36 \%$ to $95 \%$.

For most body segments, at least $50 \%$ of the observed joint angles were in the neutral range, while a number of the observed postures of the upper extremity were in the effort range (see table A1 in the appendix) rather than in the neutral range. These results were consistent with $\mathrm{Hy}$ pothesis 2 .

\section{Relative neutral-tendencies among body segments}

A descriptive analysis was performed to assess the neutral-tendency for each of the dependent variables. The total variance of all observations was computed for each dependent variable and used to measure the neutral-tendency of the joint and adjacent segments.

An $F$-test was performed to compare the total variance of each pair of adjacent segments/joints. The trunk was found to have a greater neutraltendency than the upper extremity in fore-and-aft, left-and-right, and twist movements. For the upper extremities, the wrist/hand had a greater neutral-tendency than the forearm and the upper arm; and the forearm was more likely to be rotated away from a neutral posture than the upper arm (humerus). Furthermore, the subjects were more likely to move the hip location on the seat than to deviate the other segments from a neutral posture. These posture behavior patterns were consistent

Table 6

The observed postures within the neutral range during right-handed reach. (See table A1 in the appendix for definition of neutral range.)

\begin{tabular}{|c|c|c|c|c|c|}
\hline \multirow[t]{2}{*}{ Segment posture } & \multirow{2}{*}{$\begin{array}{l}\text { Mean } \pm \text { std. dev. }{ }^{\alpha} \\
(\%)\end{array}$} & \multicolumn{4}{|c|}{ Within the neutral range } \\
\hline & & $30 \%$ & $50 \%$ & $70 \%$ & 908 \\
\hline Trunk lateral bending & $95 \pm 4$ & Yes & Yes & Yes & Yes \\
\hline Trunk flexion-extension & $78 \pm 9$ & Yes & Yes & Yes & No \\
\hline Trunk twist angle & $83 \pm 10$ & Yes & Yes & Yes & No \\
\hline Shoulder add.-abduction & $62 \pm 5$ & Yes & Yes & No & No \\
\hline Shoulder flex.-ext. & $36 \pm 5$ & Yes & No & No & No \\
\hline Humeral rot. angle & $66 \pm 13$ & Yes & Yes & No & No \\
\hline Elbow angle & $49 \pm 14$ & Yes & Yes & No & No \\
\hline Forearm rotation angle & $43 \pm 3$ & Yes & No & No & No \\
\hline Wrist flex.-ext. angle & $70 \pm 17$ & Yes & Yes & Yes & No \\
\hline Wrist deviation angle & $48 \pm 8$ & Yes & Yes & No & $\therefore 0$ \\
\hline
\end{tabular}

The sample size for the standard deviation calculation was 2 (replications) $\times 3$ (subjects) $=6$. 
with Hypothesis 3, except the neutral-tendencies at the hip and wrist/hand.

\section{Shifting of seat location (hip-shifting) at different factor levels}

The results of the hip-shifting analyses demonstrate that subjects shifted their hips when the target location was too far away (roughly twothirds of or greater than the length of an upper extremity). This behavior partially confirmed with Hypothesis 4. The results of the hip-rotation analysis also demonstrates that subjects were more likely to rotate their hips rather than twist their trunk in manipulating the targets at the different locations. These findings imply that a seat that swivels and moves forward and aft would be beneficial for workers who must move their upper bodies in response to manual demands.

\section{Discussion}

\section{Method}

The pilot studies have shown that the posture evaluation method is a useful technique to determine the factors relevant to the body postures, the posture preference of the body segments, and the postural behavior of the limbs. It can be used on other tasks such as VDT work, inspection, bench assembly, etc. The posture classification, apparatus, and the data analysis procedures for the further studies would be similar to those of the demonstrated applications. The experimenters can choose their own independent variables, select the joints of interest, and select experiment designs to evaluate postural behavior. The behavior patterns in a large population can then be used to develop guidelines for workstation design.

\section{Experimental design}

The study of postural behavior during the performance of industrial tasks typically involves multiple workplace factors and multiple joint postures. In order to identify target variables (workplace factors) that had significant effects on a set of dependent variables (multiple joint postures) through a relatively small, low-cost experiment, a fractional factorial design was used in the manual reach study. The variables that were identified as important can then be investigated more thoroughly in subsequent experiments. The potential disadvantage of a fractional factorial design is that higher-order interaction effects might be confounded with the main effects. In the right-handed reach study (a $1 / 2$ of $2 \times 3^{4}$ design), however, all main effects and all two-factor interactions could be estimated without confounding (Connor and Young, 1961).

\section{Target size effect during visual tasks}

Although the contribution of target size to segment postures during visual tasks was small $\left(R^{2}<\right.$ 0.05 ) relative to the contribution of the other main factors for all of the dependent variables, this finding may have been due to the relatively small range for target size (visual angles of $0.7^{\prime}, 1.2^{\prime}$, and $1.7^{\prime}$ ). Target size was found to be a statistically significant factor for several dependent variables, including hip-shifting distance (table 4). Subjects shifted hips further at the $0.7^{\prime}$ visual angle than at the $1.2^{\prime}$ and $1.7^{\prime}$ levels. This is not surprising since a $1^{\prime}$ visual angle is the threshold of acuity for people with 20/20 vision (Grether and Baker, 1972).

\section{Target support type effect during manual tasks}

It has been well known that the shape and/or orientation of the tool handle can force operators to use specific hand/wrist orientations and thus may also influence their upper-extremity posture (Tichauer, 1978; Armstrong, 1983). In this manual reach study, the objective was to study the preferred posture. Spherical hand grips were used to avoid forcing the subjects to use specific orientations of the wrists/hands. Furthermore, the type of support used to hold targets (supported versus non-supported) instead of grip orientation was studied. Although the type of support was found to be a statistically significant factor for several dependent variables, it was not practically significant $\left(R^{2}<0.05\right)$ for most of the dependent variables (table 5 ). This finding may have been caused by subject behavior. Subjects held the target rather than resting the hand on the target while performing supported reaches. This technique is similar 
to the technique used to perform non-supported reaches.

\section{Eye posture behavior: Horizontal and vertical view-} ing angles

While postures at most segments and joints were affected by the target location and body size, the small standard deviation of the overall horizontal viewing angle $\left( \pm 5^{\circ}\right)$ implied that the horizontal viewing angle could be considered as a constant $\left(\right.$ mean $=1^{\circ}$ ) where the subjects moved the head and proximal segments in order to place the target in or near the sagittal plane of the head. If one defines a 'cone' of preferred viewing angles as the range in which $95 \%$ of all data are contained, this would mean a cone angle of approximately $10^{\circ}$ (calculated as two standard deviations) left and right of the mean preferred line. This range is slightly smaller than the $15^{\circ}$ left and right of the standard line of sight proposed by Croney (1971), Panero and Zelnic (1979), and Eastman Kodak Company (1983). This difference might result from the nature of the task. In this study, subjects were asked io identify the orientations of Landolt rings throughout a 2-minute interval, which was a highly demanding visual task. The subjects might need to use the area of the 'sharper' focus associated with foveal vision. In fact, an angle of $5^{\circ}$ to $30^{\circ}$ from the sagittal plane has been proposed as the angle for the recognition of symbols (Panero and Zelnic, 1979); and the area of the sharpest focus is $1^{\circ}$ to either side of the sight line (Blackwell and Moldauer, 1958; Taylor, 1961; Panero and Zelnic, 1979).

The vertical viewing angle was mainly related to the target vertical location (table $2 \mathrm{a}, p<0.001$, $R^{2}=0.38$ ). The vertical viewing angles corresponding to the $60^{\circ}, 0^{\circ}$, and $-60^{\circ}$ target vertical locations were $1^{\circ} \pm 5^{\circ},-15^{\circ} \pm 6^{\circ}$, and $-15^{\circ} \pm 14^{\circ}$. With the small variances of these angles, these mean values can be considered the preferred vertical viewing angles. Previous design guides have suggested that $10^{\circ}$ or $15^{\circ}$ below horizontal was the preferred vertical viewing angle (Van Cott and Kinkade, 1972; McCormick and Sanders, 1982). Grandjean et al. (1984) reported an angle of $9^{\circ} \pm 4.5^{\circ}\left(2^{\circ} \sim 26^{\circ}\right.$ range $)$ from the horizontal as the preferred range for VDT operators. The preferred viewing angle obtained from this study was not different from that of the previous reports when the visual target was at about or below eye height; however it was different from previous recommendations when the target was located above eye height.

One should assume that the neck/head is normally tilted slightly forward with respect to a long axis established by the trunk during normal erect sitting (Kroemer and Hill, 1986). The normal neck/head tilt angle plus vertical viewing angle can be used in determining the preferred vertical location of visual display relative to the upright seated eye height. Considering an average of $13^{\circ}$ forward tilt of the neck/head, which was found in the study at normal erect sitting, and an average of $10^{\circ}\left( \pm 12^{\circ}\right)$ downward preferred eye vertical rotation observed in the study, one would expect a preferred visual location approximately $23^{\circ}$ below the horizontal. This value agrees with that $\left(25^{\circ}\right)$ suggested by Eastman Kodak Company (1983) for seated reading. Previous studies have also reported the preferred vertical visual location as $40^{\circ}$ below horizontal for seated work (Eastman Kodak Company. 1983$)$; or $38^{\circ}\left( \pm 6.3^{\circ}\right)$ below the horizontal for assembly and manufacturing tasks that require precise vision (Lehmann and Stier, 1961). This may indicate a trade-off between elevating the shoulders versus reducing the vertical viewing angle in jobs which combine visual and manual demands.

\section{Upper arm posture behavior}

It was found that when performing right-handed tasks, subjects preferred $30^{\circ}$ to $60^{\circ}$ shoulder abduction and slight lateral humeral rotation. Thus, it is suggested that when doing one-handed tasks, the primary objects should be placed slightly lateral to the shoulder location.

\section{Lower arm posture behacior: Elbow angle}

The elbow angle was related to the target distance. The angle at the furthest target distance was greater than that at the intermediate distance and at the shortest distance. A previous study recommended that the elbow angle be maintained at $90^{\circ}$ to $135^{\circ}$ (Morgan et al., 1963). About 40\% to $50 \%$ of the observed elbow angles were consistent with this recommendation; however, a number of 
observations at the far and intermediate target distances were greater than $135^{\circ}$. The subjects used the effort range of the elbow angle at these two target distance levels. This may indicate a trade-off between a flexion of the trunk versus an extension of the forearm (elbow angle) in jobs which require reaches that exceed the length of the upper extremity. Subjects preferred an approximate $90^{\circ}$ elbow angle for short reaches, while they extended their elbows to an approximate $150^{\circ}$ elbow angle (in order to reduce trunk flexion) when reaching for targets at the intermediate or far distance. Furthermore, all the observed elbow angles were found to be greater than $50^{\circ}$ (note that the range-of-motion limit for elbow flexion was $35^{\circ}$ ) This suggests that subjects did not voluntarily hyper-flex their elbows. Through a trigonometric procedure, it was determined that a target-to-shoulder distance should be greater than one-third of the length of an upper extremity to eliminate the need for hyperflexion to an angle of fifty degrees.

\section{Relative neutral-tendencies}

The rank of the neutral-tendencies from the greatest to the least during visual tasks were the eye, the trunk, the neck, and finally the hip; and the neutral-tendencies during manual tasks were the wrist/hand, the trunk, the forearm/upper arm, and finally the hip. These observed posture behaviors are not completely consistent with the theories which predict posture preference based on energy consumption or load moment considerations. Although minimizing local muscle exertions appears to explain posture behavior at the trunk relative to the shoulder and neck/head, it does not explain posture behavior at the eye, wrist/ hand, and hip. These differences might result from the nature of the task. As discussed in the 'Eye posture behavior' section, subjects were performing a static task with high visual demands throughout a two-minute interval. The subjects might need to use their foveal vision to identify the orientations of the targets thus explaining the greater neutral-tendency at the eye than at the other segments. In addition, the subjects were not forced to use specific orientations of the wrist/ hand during the manual task experiments, thus explaining the greater neutral-tendency at the wrist/hand than at the other segments. Furthermore. the seat design used in the study was a simple horizontal seat pan with no support for the back or pelvis. It was intended to facilitate movements of the hips (translation and/or rotation) and thus might account for the greater hip movements (and reduced movements of the trunk and neck) found in the study.

Practical applications of results on workstation design

Based on the postural behavior observed in these preliminary application studies, several guidelines for workstation design are proposed:

(1) For the horizontal location of visual displays, the most frequently used targets should be placed in the central viewing area of a workstation as close as possible to the sagittal plane of the head/eyes (within approximately $10^{\circ}$ ). This is necessary for foveal vision.

(2) For the vertical location of visual displays placed in vertical, the primary display locations should be $10^{\circ} \sim 35^{\circ}$ below the upright seated eye height, and the secondary display locations go to $5^{\circ}$ above to $10^{\circ}$ below or $35^{\circ}-45^{\circ}$ below the upright seated eye height.

(3) The target size for the visually demanding tasks should be a visual angle of one minute or greater (Grether and Baker. 1972) to avoid severe trunk or neck flexion/extension or hip relocation to the edge of seat.

(4) The manual targets that are used most frequently should be placed with the target-toshoulder distance greater than one-third of the length of an upper extremity to avoid trunk extension or severe elbow flexion.

(5) A free-swivel feature of the seat pan for the work seat is suggested. This promotes hip rotation allowing the trunk and neck to avoid twisted postures.

(6) A seat allowing fore-and-aft translation is suggested for performing unconstrained static, manual seated tasks which do not require high levels of manual precision, especially if several widely dispersed targets are used. This encourages hip/body movement while allowing the trunk to stay in neutral range. This recommendation is limited to jobs which do not require high exertions of the hand in the hori- 
zontal plane. In such a situation, a stable seat may be required to provide the necessary reaction forces.

(7) When doing one-handed tasks, the targets that are manipulated most frequently should be placed slightly lateral of the shoulder. This allows to avoid trunk lateral bending, and severe shoulder abduction or adduction.

\section{Further applications}

Due to the limited scope of the application studies, several points must be considered when assessing the observed behavior patterns and developing guidelines for workstation layout. Only three subjects representing small (5th\%), average $(50$ th $\%)$ and tall $(95$ th\%) persons were used in the studies, and the body-size effect was confounded with the subject effect. To investigate the contribution of body size with no confounding, a further study using multiple subjects with similar body sizes would be required. This will also allow for obtaining the more 'general' guidelines for workstation design.

The postural behavior observed during manual tasks in the investigations were based on tasks that required no loads or very light loads on the hands. Further research using varying loads on hands should be performed to evaluate posture under strength-constrained conditions. Furthermore, spherical (i.e. orientation-free) hand grips were used in this experiment. If specific orientations of the wrist/hand are required (as found in many work situations), the upper extremity posture may be different. Further investigations are needed to understand upper extremity posture under 'forced' wrist orientations.

All the behavior patterns found in these studies were based on tasks that were performed for two minutes. Fatigue was not found to be significant for any joints/segments. The subjects may have been highly motivated to keep their postures stable and thus did not change their postures during the two-minute observation period; therefore a longer study may be required to identify the impact of fatigue on postural behavior. Furthermore, further research on behavior patterns during dynamic tasks ts suggested to test if hip-shifting behavior and the neutral-tendency of body seg- ments are similar to the patterns observed during the static tasks used in this investigation.

Finally, this research used static, visually demanding and manual reach tasks in a laboratory setting as a test-bed. Further application on other tasks, such as bench assembly, inspection, and VDT work are recommended.

\section{Conclusions}

This study presented an investigation method of postural behavior of the trunk, neck/head. eye, and upper extremity. The pilot studies showed that the method is a useful technique to determine the factors relevant to the body postures, the posture preference of the body segments, and the postural behavior of the limbs. The application study results suggested that the postures were affected by target location, body size, target size. The preferred horizontal location of simple visual task was within $10^{\circ}$ of the sagittal plane of the head/eyes. The preferred vertical location of visual display was $10^{\circ}$ to $35^{\circ}$ below the upright seated eye height. In addition, when doing onehanded tasks, it was recommended to place the object slightly lateral of the shoulder. Furthermore, free-swivel and fore-and-aft-translation features of the seat are suggested for performing unconstrained static seated tasks. This posture evaluation methodology can be used for further applications on other tasks such as VDT work, inspection, and bench assembly. With more subjects for each application study, one should be able to obtain general behavior patterns which can be used to develop guidelines for workstation design.

\section{Acknowledgements}

This research was supported in part by the Ford Motor Company. Additional support was provided by the University of Michigan Center for Ergonomics and a National Needs Fellowship from the US Department of Education. The authors would like to thank Professor D. Chaffin, Professor G. Herrin, Professor P. Loubert, and Professor R. Worringham for their contributions to the study design and analysis. 


\section{Appendix}

\section{Definitions}

Frankfurt plane: The Frankfurt plane (FP) is established by the tragia (approximately the earholes) and the lowest point of the orbits (eye sockets) (Webb Associates, 1978). It coincides with the horizontal when the neck/head is held straight up.

Upright posture: The upright posture of the seated upper body was defined as that with the mid-hip at the original position (defined below), the trunk and neck/head vertical with no rotation, the Frankfurt plane parallel to the horizontal, and the upper arms hanging downward, parallel to the trunk, the forearm parallel to the sagittal plane of the trunk with the elbows at a $90^{\circ}$ included angle, the palms facing the sagittal plane of the trunk, and no radial-ulnar deviation or flexion-extension of the wrist (figure A1). In addition, the upright position of the hips prior to any experimental treatment was defined as the original position on the seat.
Shoulder height: The height of the 2 nd thoracic vertebra (T2) relative to the seat (hips) position when sitting upright.

Adjacent segment: A segment which shares a joint with another segment.

Neutral posture: The posture of minimal discomfort to the joint and/or adjacent body segments.

Neutral range: The range of motion which presents minimal discomfort to the joint and adjacent body segments (table A1 and figure A2).

Effort range: The range-of-motion that can be achieved with mild discomfort to the joint and adjacent body segments (table $\mathrm{Al}$ and figure A2).

Maximum range: The maximum limits of a joint's range-of-motion (table $\mathrm{A} 1$ and figure $\mathrm{A} 2$ ).

Proximal segment: The segment closer to the worker-chair interface (the hips). For example, the trunk is a proximal segment relative to the upper arm, and the pelvis link is the most proximal segment.

Distal segment: The segment farther away from the hips.

Table A1

The range limits of postures of the trunk and upper body (see figure A2).

\begin{tabular}{|c|c|c|c|c|c|}
\hline Posture & Neutral range $^{a}$ & Effort range $^{2}$ & Max. range ${ }^{a}$ & Ref. $^{b}$ & Fig. $=$ \\
\hline Viewing angle (vertical) & $-45^{\circ}-15^{\circ}$ & & $-70^{\circ}-48^{\circ}$ & 3 & A2a \\
\hline Viewing angle (horizontal) & $-15^{\circ}-15^{\circ}$ & & $-30^{\circ}-30^{\circ}$ & 11,12 & $A 2 b$ \\
\hline Neck/head vertical angle & $-45^{\circ}-45^{\circ}$ & & $-75^{\circ}-75^{\circ}$ & 10,13 & A2d \\
\hline Neck/head rotation angle & $-20^{\circ}-20^{\circ}$ & $-45^{\circ}-45^{\circ}$ & $-80^{\circ}-80^{\circ}$ & 10,11 & A2e \\
\hline Neck/head lateral angle & $-20^{\circ}-20^{\circ}$ & & $-35^{\circ}-35^{\circ}$ & 10 & $\mathrm{~A} 2 \mathrm{f}$ \\
\hline Trunk flexion-extension & $-30^{\circ}-30^{\circ}$ & & $-70^{\circ}-30^{\circ}$ & 13,9 & $A 2 g$ \\
\hline Trunk twist/rotation angle & $-20^{\circ}-20^{\circ}$ & & $-42^{\circ}-42^{\circ}$ & 13,10 & A. $2 \mathrm{~h}$ \\
\hline Trunk lateral bending & $-20^{\circ}-20^{\circ}$ & & $-40^{\circ}-40^{\circ}$ & 13,9 & $\mathrm{~A} 2 \mathrm{i}$ \\
\hline Wrist extension-flexion & $-15^{\circ}-15^{\circ}$ & $-45^{\circ}-$ & $-85^{\circ}-85^{\circ}$ & 1,7 & A2k \\
\hline Wrist deviation angle & $-15^{\circ}-5^{\circ}$ & $-40^{\circ}-25^{\circ}$ & $-45^{\circ}-40^{\circ}$ & 1,6 & A2l \\
\hline Elbow included angle & $70^{\circ}-135^{\circ}$ & $50^{\circ}--160^{\circ}$ & $35^{\circ}-180^{\circ}$ & 39 & A2m \\
\hline Forearm rotation angle & $-90^{\circ}--30^{\circ}$ & $-120^{\circ}-30^{\circ}$ & $-180^{\circ}-90^{\circ}$ & $2,7,8$ & $A 2 n$ \\
\hline Shoulder extension-flexion & $-27^{\circ}-45^{\circ}$ & $-45^{\circ}-$ & $-61^{\circ}-188^{\circ}$ & 4,5 & A2p \\
\hline Shoulder add.-abduction & $-45^{\circ}-20^{\circ}$ & $-90^{\circ}-$ & $-134^{\circ}-48^{\circ}$ & 4,8 & $A 2 q$ \\
\hline Humeral rotation angle & $-20^{\circ}-45^{\circ}$ & & $-34^{\circ}-97^{\circ}$ & 8 & $A 2 r$ \\
\hline
\end{tabular}

\footnotetext{
Neutral range: the range of motion which presents minimal discomfort to the joint and adjacent body segments; Effort range: the range-of-motion that can be achieved with mild discomfort to the joint and adjacent body segments; Maximum range: the maximum limits of a joint's range-of-motion.

${ }^{b} 1$. Armstrong et al. (1982) 2. Kroemer (1964) 3. Morgan et al. (1963). Tichauer (1978), Singleton (1982) 4. Hagberg (1984) 5. Keyserling (1986) 6. Youm et al. (1978) 7. Kapandji (1970) 8. Webb Associates (1978) 9. Batch (1955) 10. Kapandji (1974) 11. Panero and Zeinik (1979) 12. Eastman Kodak Company (1983) 13. Information from anatomical data, biomechanical concepts and non-experimental reports.
} 
Table A2

Directional signs of body segment rotations.

\begin{tabular}{lll}
\hline Segment & Positive sign $(+)$ & Negative sign $(-)$ \\
\hline Viewing angle (vertical) & Upward rotation & Downward rotation \\
Viewing angle (horizontal) & Left rotation & Right rotation \\
Neck/head vertical angle & Extension & Flexion \\
Neck/head rotation angle & Left rotation & Right rotation \\
Neck/head lateral angle & Right bending & Left bending \\
Trunk flexion-extension & Extension & Flexion \\
Trunk twist/rotation angle & Left rotation & Right rotation \\
Trunk lateral bending & Right bending & Left bending \\
Wrist flexion-extension & Flexion & Extension \\
Wrist deviation & Radial deviation & Ulnar deviation \\
Elbow angle & Always positive & - \\
Forearm rotation angle & Supination & Pronation \\
Shoulder flexion-extension & Flexion & Extension \\
Shoulder add.-abduction & Adduction & Abduction \\
Humeral rotation angle & Medial rotation & Lateral rotation \\
Hip rotation angle & Left rotation & Right rotation \\
\hline
\end{tabular}

Reference posture: the position of a joint or segment that is used to distinguish/define the direction of the motion of the joint or the orientation of the segment.
Joint angle/Segment posture: The angle(s) of a segment relative to its reference posture measured from the proximal end of the segment.

Neutral-tendency: The tendency for a joint/

Z

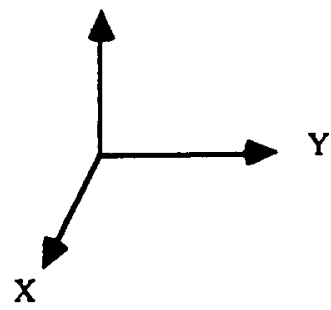

Plan View

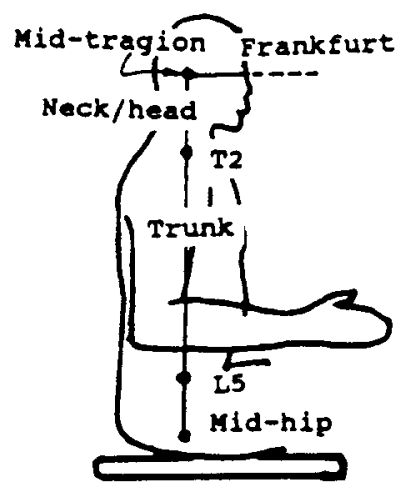

a. Upright body posture

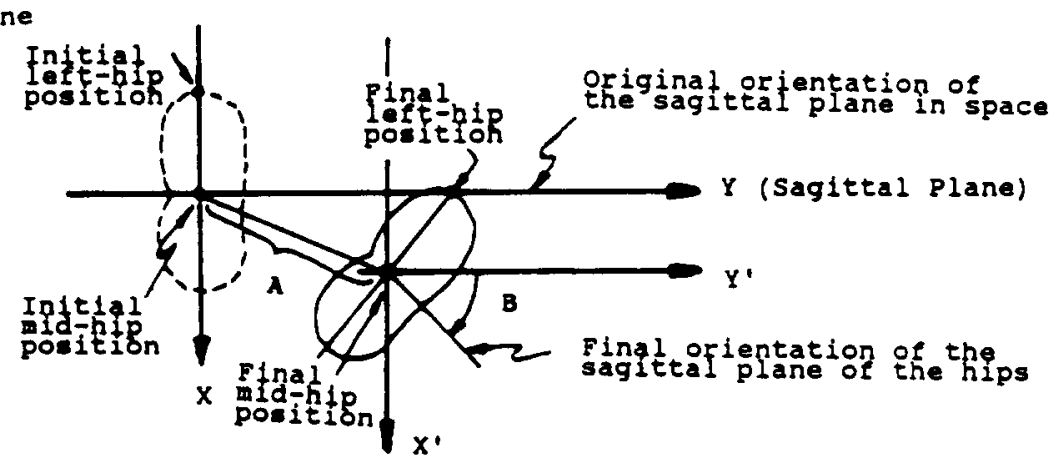

b. A: Hip-shifting distance, B: Hip-rotation angle

Fig. A1. Upright body posture and hip shifting. 
segment to remain within the neutral range. A segment that is more likely to stay within its neutral range is considered to have greater neutral-tendency than segments that are likely to move outside their neutral ranges.

\section{Posture classification}

Hip-shifting distance: The final mid-hip position relative to its original seated position (figure A1).

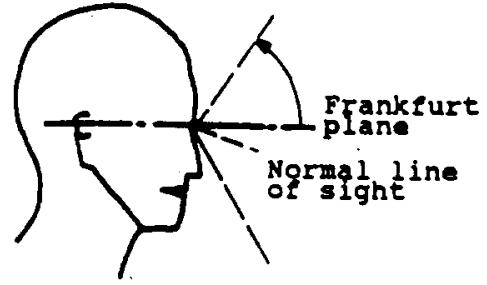

a. Vertical viewing angle

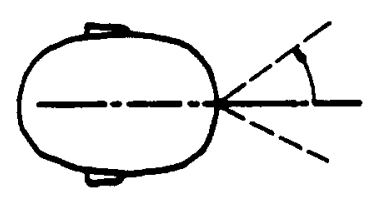

b. Horizontal viewing angle

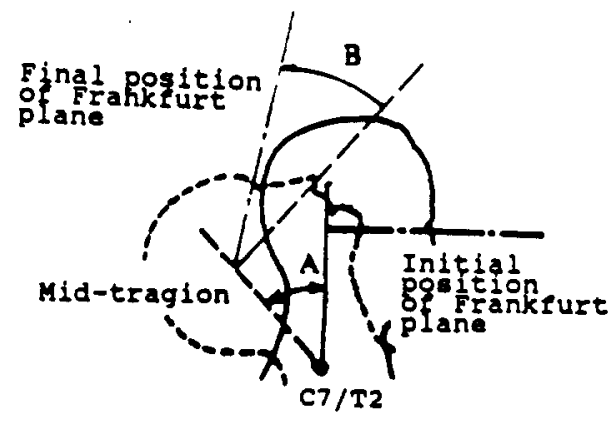

c. A: Neck vertical movement B: Head vertical movement

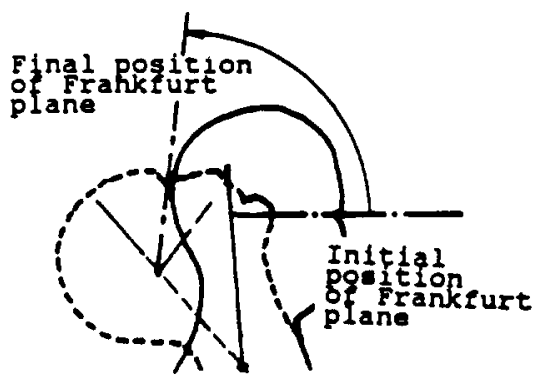

$\mathrm{C7} / \mathrm{T2}$

d. Neck/head vertical angle

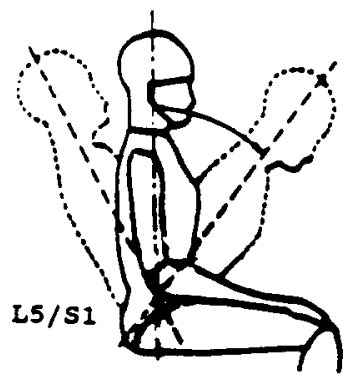

g. Trunk vertical angle

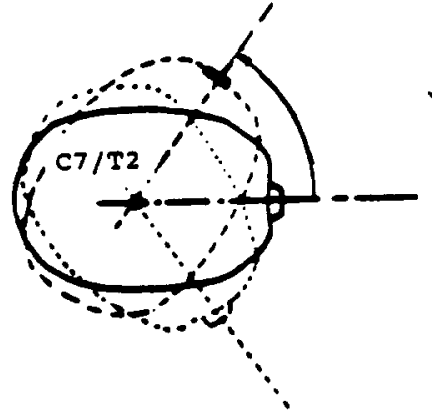

e. Neck/head rotation angle

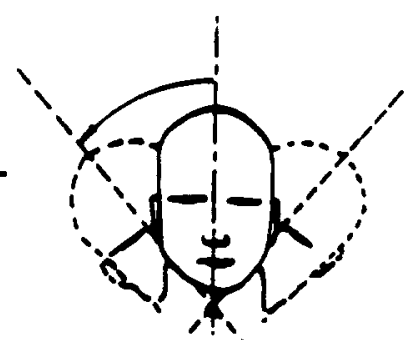

$C 7 / T 2$

f. Neck/head lateral bending angle

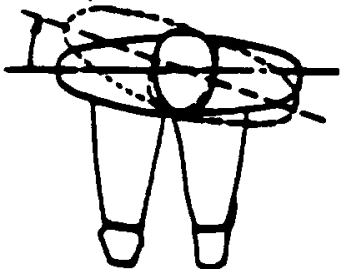

h. Trunk rotation angle

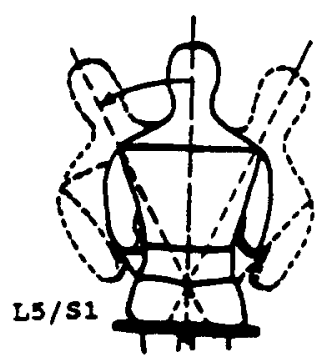

i. Trunk lateral bending angle

Fig. A2. Seated body segment postures and their anatomical angles (see table A1). 


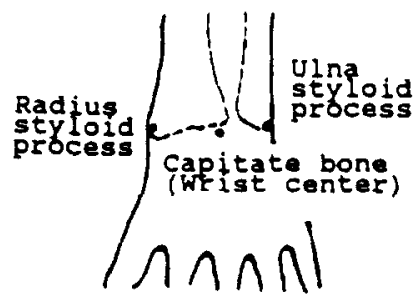

(Right hand, Palm view)

j. Wrist joint

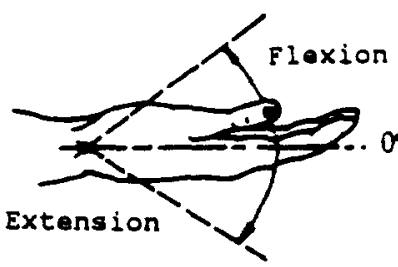

k. Wrist flexion-extension

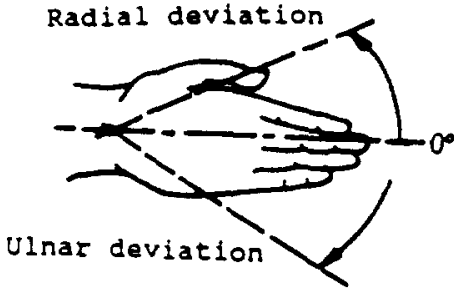

1. Wrist deviation

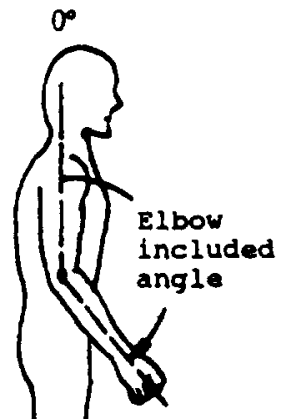

m. Elbow angle

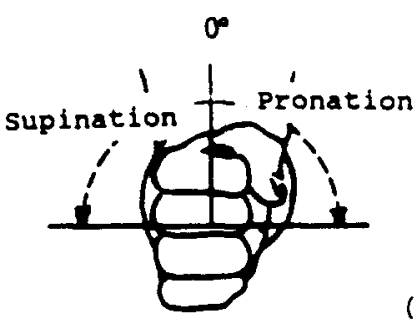

n. Forearm rotation angle

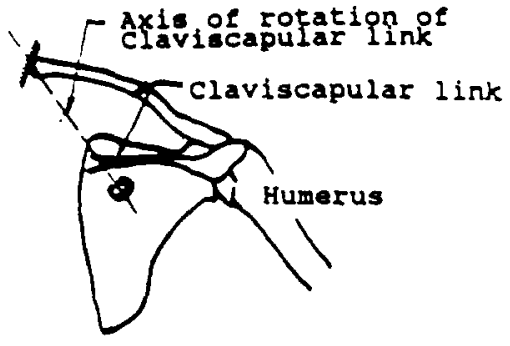

(Right shoulder, Posterlor view)

o. Shoulder complex

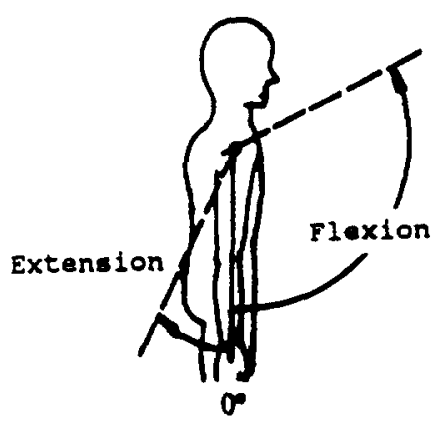

p. Shoulder flexion-extension

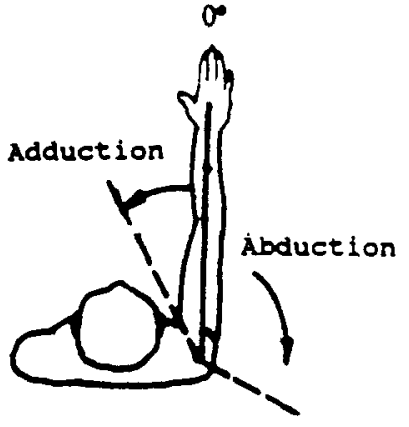

q. Shoulder adduction-abduction

r. Shoulder intemal-extemal rotation

Fig. A2 (continued).

Hip-rotation angle: The final orientation of the sagittal plane of the hips relative to its orientation in the original seated position (figure A1).

Viewing angles: Eye-to-target angles relative to the Frankfurt plane and sagittal plane (figures A2a and $\mathrm{A} 2 \mathrm{~b}$ ).

Neck/head angles: Changes in Frankfurt plane relative to horizontal without moving the trunk and hips (figures A2d, A2e, and A2f). That is, the changes of head/neck relative to the 7 th cervical/2nd thoracic vertebra (C7/T2) with three degrees of freedom: vertical angle (flexion-extention angle), rotation angle, and lateral bending angle.

Trunk posture: The change in position of the $1 \mathrm{st} / 2$ nd thoracic vertebra location when the 
motions are assumed to be centered at the disc between the 5 th lumbar and 1st sacral vertebrae $(\mathrm{L} 5 / \mathrm{S} 1)$. It is equivalent to a joint with three degrees of freedom: flexion-extension, axial rotation (or twist), and lateral bending (figures $\mathrm{A} 2 \mathrm{~g}, \mathrm{~A} 2 \mathrm{~h}$, and $\mathrm{A2 \textrm {i }}$.

Wrist posture: Hand location described relative to the base of the capitate bone (wrist center) (Youm et al., 1978) (figure A2j). This wrist center is approximately the midpoint of an imaginary segment connecting the styloid processes of the radius and ulna. The wrist flexion-extension and radial-ulnar deviation angles are illustrated in figures $\mathrm{A} 2 \mathrm{k}$ and $\mathrm{A} 2 \mathrm{l}$ with motion centered at the wrist center.

Elbow posture: The included angle between the upper arm and forearm (figure $\mathrm{A} 2 \mathrm{~m}$ ).

Forearm posture: The pronation or supination angle of the forearm relative to its standard 'reference' posture (figure $\mathrm{A} 2 \mathrm{n}$ ). The 'reference' forearm posture occurs when the forearm is placed with the ulnar border of the hand down and the radial border up. Supination is obtained by rotating the forearm outward with the palm of the hand being turned up, while pronation is obtained by rotating the forearm inward, turning the palm down (Batch, 1955).

Shoulder posture: The upper-arm posture relative to the trunk (figures $A 2 p, A 2 q, A 2 r$ ). The shoulder complex can be viewed as a mechanism consisting of the humerus and the claviscapular (or scapular) link (figure A20). Viewed as a whole, the shoulder complex (humerus plus scapula) has flexion-extension, adductionabduction, and medial-lateral rotation (humeral rotation) functions. The reference position of shoulder flexion-extension movements with the spine erect occurs when the arms are hanging straight down by the sides; the reference position of shoulder adduction-abduction occurs when the arms are flexed $90^{\circ}$, parallel to the sagittal plane of the spine; and the reference position of humeral rotation occurs when the upper arms are at the reference flexion-extension position and the forearm is parallel to the sagittal plane of the spine.

The neutral, effort, and maximum posture ranges of the body segments are listed in table A1.
The signs of the directional rotation of the segment postures are listed in table $\mathrm{A} 2$.

\section{References}

Armstrong, T.J., 1983. An Ergonomics Guide to Carpal Tunnel Syndrome. AIHA Ergonomics Guide Series, Amer. Ind. Hygiene Association, Akron, Ohio.

Armstrong, T.J., Foulke, J.A., Joseph, B.S. and Goldstein, S.A., 1982. Investigation of Cumulative Trauma Disorders in a Poultry Processing Plant. American Industrial Hygiene Association.

Bapu, P., Kikta, M., Korna, M. and McDaniel, J., 1982. User's guide for COMBIMAN programs, AFAMRL-TR-81-151, Air Force Aerospace Medical Research Laboratory, Wright-Patterson Air Force Base, Ohio.

Batch, J.W., 1955. Measurements and recording of joint function. United States Armed Forces Medical Journal. 6 (3): 359-382.

Blackwell, H.R. and Moldauer, A.B., 1958. Detection thresholds for point sources in the near periphery. Project 2455. University of Michigan Engineering Research Institute.

Carlyle. L., 1960. Man and space. Douglas Aircraft Co., Engineering Paper No. 899.

Connor. W.S. and Young, S., 1961. Fractional Factorial Designs for Experiments with Factors at Two and Three Levels. National Bureau of Standards.

Croney, J., 1971. Anthropometrics for Designers. B.T. Batsford Ltd., London.

Drillis, R. and Contini, R., 1966. Body Segment Parameters, BP174-945, Tech. Rep. No. 1166.03, School of Engineering and Science, New York University, New York.

Eastman Kodak Company, 1983. Workplace, equipment and environmental design and information transfer. Ergonomic Design for People at Work, 1. Lifetime Learning Publications, California.

Grandjean, E., Hunting, W. and Nishiyama, K., 1984. Preferred VDT workstation settings, body posture and physical impairments. Applied Ergonomics, 15 (2): 99-104.

Grether, W.F. and Baker, C.A., 1972. Visual presentation of information. In: H.P. Van Cott and R.G. Kinkade (Eds.), Human Engineering Guide. U.S. Government Printing Office.

Dempster, W.T., 1955. Space requirements of the seated operator. WADC Tech. Report 55-159, Wright Air Development Center, Ohio.

Hagberg. M., 1984. Occupational musculoskeletal stress and disorders of the neck and shoulder: A review of possible pathophysiology. Int. Arch. Occup. Environ. Health, 53: 269-278.

Healy, M.J., Katz, R., Vaughn, R.R., Ryter, J.S. and Springer, W.E., 1969. Cockpit geometry evaluation, Phase I. Final Report, 4 - Mathematical model, Boeing-JANAIR Report 690104.

Hsiao, H. and Keyserling, W.M., 1990. A three-dimensional ultrasonic system for posture measurement. Ergonomics, 33 (9): 1089-1114. 
Kapandji. I.A., 1970. Upper limb. The Physiology of the Joints, 1. Translated by L.H. Honore. Churchill Livingstone. Edinburgh and London.

Kapandji. I.A.. 1974. The trunk and the vertebral column. The Physiology of the Joints, 3. Translated by L.H. Honore. Churchill Livingstone, Edinburgh and London.

Keyserling. W.M., 1986. Posture analysis of the trunk and shoulders in simulated real time. Ergonomics, 29 (4): 569583.

Kilpatrick. K.E., 1970. A model for the design of manual work stations. Ph.D. thesis. The University of Michigan. Ann Arbor, Michigan, USA.

Kroemer K.H.E. and Hill S.G., 1986. Preferred line of sight angle. Ergonomics. 29 (9): 1129-1134.

Lehmann, G. and Stier, F., 1961. Mensch und Gerat (Humans and equipment). Handbuch der gesamten Arbeitsmedizin, 1: 718-788. Urban \& Schwarzenberg. Berlin.

McCormick, E.J. and Sanders, M.S., 1982. Human Factors in Engineering and Design. 5th ed. McGraw-Hill, New York.

Morgan, C., Cook, J.. Chapanis, A. and Lund, M. (Eds.), 1963. Human Engineering Guide to Equipment Design. McGraw-Hill, New York.

Panero, J, and Zelnik, M., 1979. Human Dimension \& Interior Space. Whitney Library of Design, The Architectural Press Ltd., London.

Singleton, W.T., 1982. The Body at Work - Biological Ergonomics. Cambridge University Press, Cambridge and London.
Snyder. R.G., Chaffin, D.B. and Schutz, R.K., 1972. Link system of the human torso. HSRI Report 71-112, Highway Safety Research Institute. University of Michigan. Ann Arbor. Michigan and AMRL-TR-71-88, Aerospace Medical Research Laboratories, Ohio.

Systat Inc., 1985. MGLH programs. The System for Statis. Evanston, IL, USA.

Taylor, J.H., 1961. (Cited from H.P. Van Cott and R.G. Kinkade, 1972), Contrast thresholds as a function of retinal position and target size for the light-adapted eye. REF. 61-10. Scripps Institution of Oceanography.

Tichauer. E.R., 1978. The Biomechanical Basis of Ergonomics - Anatomy Applied to the Design of Work Situations. Wiley, New York.

Van Cott, H.P. and Kinkade, R.G., 1972. Human Engineering Guide to Equipment Design. U.S. Government Printing Office, Washington, DC.

Webb Associates, 1978. Anthropometric Source Book, 1. . AASA 1024, National Aeronautics and Space Administration. Washington, DC.

Youm Y., McMurtry, R.Y., Flatt, A.E. and Gillespie. P.E., 1978. Kinematics of the wrist: 1. An experimental study of radial-ulnar deviation and flexion-extension. $\mathbf{J}$; Bone \& Joint Surg., 60: 423-431.

Yu, C.. Keyserling, W.M. and Chaffin, D.B., 1988. Development of a work seat for industrial sewing operators: Results of a laboratory study. Ergonomics, 31 (12): 1765-1786. 